\title{
Assessment of Modifiable and Non modifiable Risk factors associated with acute stroke at Assuit university hospital.
}

\author{
Sanaa saber Mohamed, Mohammed Hossam El-dean Hassan, Mona Aly Mohammed, \& Mervat Anwer \\ AbdEl-Aziz.
}

Demonstration Critical care nursing department, faculty of nursing, Sohage University.

Professor of intrinsic medicine, Faculty of Medicine, Assuit University.

Lecturer in Critical Care Nursing Department, Faculty of Nursing, Assuit University.

Lecturer in Critical Care Nursing Department, Faculty of Nursing, Assuit University

\begin{abstract}
Aim of the studyTo investigate the prevalence of modifiable and non modifiable risk factors associated with acute stroke Retrospective research design was used. This study was carried out at Emergency department at Assiut University Hospitals. The sample of this study was consisted of 60 patients, admitted to Emergency department with acute stroke. Tool used in this study consisted of an assessment sheet developed by the researcher for identifying the risk factors commonly associated with types of acute stroke. This tool comprised two main parts, part I: - Assessment of socio-demographic and clinical data. part II: - assessment of acute stroke risk factors. The main results: revealed significant difference between both groups regard type of acute stroke $(\mathrm{p}<0.03)$. The result of the current study revealed that majority of the study sample was old age with no significant difference. Also majority of the study sample were females in both ischemic and hemorrhagic acute stroke. The current study revealed that hypertension is the first and major cause of acute ischemic or hemorrhagic stroke. Risk factors associated with acute stroke show no significant difference between both group with (46.66\%) for hypertension, (10.0\%) for DM, (15.0\%) for obesity and IHDs. conclusion: age and hypertension are the most significant risk factors for incidence of stroke the study sample. Recommendations: - Based on the study it is recommended to develop educational programs for raising public awareness of stroke risk factors and warning signs and identifying those at risk of stroke
\end{abstract}

Key words: - Assessment, Acute Stroke, Modifiable Risk Factors \& Non Modifiable Risk Factors.

\section{Introduction}

Acute Stroke is a medical emergency that requires immediate medical attention. With active and efficient nursing management in the initial hours after stroke onset and throughout subsequent care, effective recovery and rehabilitation is increased (Jane Williams et al., 2013). Acute stroke refers to the sudden onset of acute neurological deficit persisting for more than 24 hours and caused by the interruption of blood flow to the brain. It is the third leading cause of morbidity and mortality in the united state after heart disease and cancer (National Stroke Association, 2009).

Risk factors associated with acute stroke can be divided into Non modifiable and modifiable risk factors. The Non modifiable risk factors are gender, age, race and heredity. The over all incidences are higher for men. The risk increase with the age doubles each decade after age of 55years. Acute Strokes are more common in men, but more women die from stroke than men. African American has higher incidence for stroke and death from stroke than whites (Heart and stroke foundation, 2006), a family history of prior stroke or transient ischemic attack (TIA) also increases the risk of stroke (American Heart Association, 2006).
Modifiable risk factors are those that can potentially be altered through lifestyle changes and medical treatment, thus reducing the risk of stroke. Modifiable risk factors include (Heart and stroke foundation, 2006). Hypertension is the single most important modifiable risk factor but it is still undetected and inadequate treated. Acute Stroke risk can be reducing by up to $42 \%$ with appropriate treatment of hypertension (Heart and stroke foundation, 2008). Most patients with acute stroke or TIA should be commenced on antihypertensive medication, regardless of baseline BP. (National Stroke Foundation, 2007).

Diabetes mellitus is a significant risk factor for acute stroke. The risk for acute stroke in people with DM is 4 to 5 times higher than in the general population. Elevated blood sugar level is common in patients presenting with stroke or TIA. Good glycaemic control is essential for prevention of the long term micro- and non-vascular complications of this disease (Adams et al., 2007 \& Romano, 2008). Increase serum cholesterol and smoking, where Smoking nearby double the risk for acute stroke (Carmona, 2006). Abdominal obesity, increase ischemic stroke risk in all ethnic groups. Individual who is 
overweight or obese experience large decrease in life expectancy; it associated with hypertension and increase blood glucose which increase the risk of stroke (Lewis, et al., 2007 \& American Heart Association, 2005).

Classification of stroke is based on the underlying problems, created within the cerebral artery and the blood supply to the brain. Plugging by atherosclerosis or clots creates a narrowing lumen preventing adequate blood flow to cerebral tissue. Rupture may results from weakened vessels causing leakage of blood into the brain or subarchinoide space. Thus stroke divided into ischemic and hemorrhagic stroke (Kuruvilla, 2007).

Primary prevention of acute ischemic stroke remains the best approach. Leading a healthy lifestyle, where includes not smoking, maintaining a healthy weight, following a healthy diet (including modest alcohol consumption), and daily excersis, can reduce the risk of having a stroke by about one half (Chiuve, et al., 2008). Primary prevention of hemorrhagic stroke is the best approach and includes managing hypertension and ameliorating other significant risk factors, Control of hypertension, especially in people older than 55 years of age; reduce the risk of hemorrhagic stroke (Luders, 2007).

Acute treatments attempt to reverse ischemia and to reduce local force and intracranial pressure. The long-term treatments for stroke focus on preventing recurrences and maximizing motor and functional capabilities. To plan long-term treatment, physicians must determine the location of the primary vascular injury and its underlying or predisposing causes (Lewis, et al., 2007).

Care of patient with acute stroke is directed toward minimizing damage resulting from stroke, maintaining adequate cerebral perfusion and decrease further damage. Stroke Mangment has two main phases: acute phase and rehabilitation phase. During the acute phase immediately after patient admission nursing care focuses on monitoring patient neurological statue, assessing the severity of stroke and prevention of complications associated with neurological deficit and immobility produced by stroke (Morton, et al, 2005).

\section{Significance of the study}

As the acute stroke constitutes a major problem, which causes excessive pain and suffering in affected patients also height mortality and morbidity rate and left patients with permanent disability placing a burden on families and communities. Stroke is a significant and increasing health issue. World Health Organization data shows that 15 million people worldwide suffer a stroke every year. Of these, five million people die from stroke and five million people are left with permanent disability placing a burden on families and communities. Awareness and modification of risk factors such as hypertension and smoking has resulted in a reduction in the incidence of stroke however the absolute number of strokes continues to rise as a result of ageing populations and increased life expectancy (Sahni R 2007). Statistics of Egyptian emergency Care Unit at Assuit University Hospital in the years of (2010 \& 2011) revealed that the number of patients admitted to emergency care unit were 375 patients.

\section{Aim of the study}

To investigate the prevalence of modifiable and non modifiable risk factors associated with acute stroke.

\section{Patient and Methods}

\section{Research design}

Retrospective research design was used to conduct this study.

\section{Setting}

The study was carried out in emergency care unit at Assuit university hospital.

\section{Sample}

A convenient sample of 60 critically ill adult patients who admitted to the emergency department.

\section{Inclusion criteria}

All patients admitted to the emergency unit with the diagnosis of acute ischemic and acute hemorrhagic stroke were included in the study who are neurologically disturbance as GCS score of less than 8 (sever disturbed patient, comatosed).

\section{Exclusion criteria}

Excluded from the current study the patients with head injury, Terminal diseases, Hepatic disease, pregnant women, Burn patient and the Patient who receive chemotherapy and those with seizure activity. Tools

One tool was developed by the researcher and used in this study. The tool was revised by a panel of 5 nursing and medical experts, and tested then piloted by the investigator. It composed of two main parts as following.

part 1: Socio-demographic and clinical data

This part was developed by the researcher based on reviewing the relevant literature and used to assess the studied patients regarding socio-demographic, medical and emergency data to form base line data to be compared with, This part includes .

\section{A) Patient's characteristics}

It includes demographic data (patient's age and sex), patient's diagnosis and the date of admission.

\section{B) Clinical data}

It includes (History of current disease, past medical diseases, life style and Medical diagnosis). 


\section{C) Emergency department data}

It includes onset of stroke and recurrence, mode of arrival and length of stay in emergency department

Part 2: - Risk factors assessment tool:-

This part used to assess type of acute stroke, its frequency and to assess frequency of modifiable and non-modifiable risk factors in each type.

\section{Methods}

This study where carried out through two main phases as following:-

\section{1-The preparatory phase}

- An official Permission to conduct the study was obtained from the hospital responsible authorities in the Emergency department after explaining the aim and nature of the study.

- An approval was obtained from the local ethical committee and the study was followed the common ethical principles in clinical research.

- The tool used in this study was developed by the researcher based on reviewing the relevant literature.

- Content validity: The tool was tested for content related validity by jury of 5 specialists in the field of critical care nursing and critical care medicine from Assuit University Hospital, and the necessary modifications were done.

- A pilot study carried out before starting of data collection to test the feasibility and clarity of the study tools on $10 \%$ of the sample, the analysis of pilot study define the modification required in the tool used, and the necessary modification was done prior to data collection. The studied subjects were excluded from the actual study.

- Protection of human rights (ethical considerations): Informed consent was obtained from each patient or from the responsible person for the unconscious patients. The investigator emphasized that the participation is voluntary and the confidentiality and anonymity of the subjects will be assured through coding the data. Subjects were assured that can they withdraw from the study at any time without any rational.

2-Implementation phase

- Purpose of the study was simply explained to patients and their relatives in case of unconsciousness.

- The researcher was started to collect data from patients on day of diagnosis as acute stroke using assessment sheet.

- The study involved 60 patients who admitted to the emergency department at Assuit university hospital in the study period. And the following data were collected om admission from patient or from relatives in case of unconscious patient

- Socio-demographic data as age and sex.
- Complete medical history was taking including history of presence of risk factors as hypertension, ischemic heart diseases, Diabetes mellitus, coagulopathy, obesity and history of previous stroke.

- The studied sample fulfilling the research criteria were assessed for type of acute stroke either ischemic or Haemorrhagic stroke through CT scanning and MRI. Stroke subtype was diagnosed and non-stroke patient were excluded.

- Then each group (ischemic and Haemorrhagic) were assessed for length of hospital stay and for number of death in each type.

- The researcher was available at the department 5 days per week at the morning and afternoon shift to collect the data from patient admitted to the department.

* The following investigations were done to define risk factors:

- Electrocardiography \& Echocardiography to define relevant cardiac problems, history of myocardial infarction, coronary artery disease, congestive heart failure, arrhythmia or valvular heart diseases.

- Blood sugar: Diabetes mellitus (DM), defined as venous plasma level of glucose $>7.0 \mathrm{moll} / \mathrm{l}(>126$ $\mathrm{mg} / \mathrm{dl}$ ) or under hypoglycemic treatment.

- Arterial hypertension defined as systolic blood pressure > $140 \mathrm{mmHg}$, diastolic blood pressure > $80 \mathrm{mmHg}$ or antihypertensive treatment.

- Family history of stroke.

- Previous history of stroke or transient ischemic attacks (TIA).

- The both group were compered to assess the rate of modifiable and non-modifiable risk factors in ischemic and Haemorrhagic type of stroke.

\section{Statistical analysis}

All data were recorded in a special chart for every patient. The collected data were coded, analyzed and tabulated .Data entry and analysis were done using SPSS 17.0 statistical software package. Data were presented using descriptive statistics in the form of frequencies and percentages for qualitative variables, and means and standard deviations for quantitative variables. Quantitative continuous data were compared using analysis of variance test in case of comparisons between two independent groups. Using chi-square test for non-parametric data to determine significant.

Statistical significant differences were considered when P-value used as follows:-

$\mathrm{P}>0.05$ non significant $\quad * \mathrm{P}<0.05$ significant

$* * \mathrm{P}<0.01$ moderate significant $* * * \mathrm{P}<0.001$ highly significant. 


\section{Results}

Table (1): prevalence of Ischemic and Hemorrhagic Stroke among studied patient $(\mathrm{N}=60)$.

\begin{tabular}{|c|c|c|c|}
\hline Variables & $\mathbf{N}$ & $\%$ & Significance test-p value \\
\hline Ischemic & 34 & 60.0 & \multirow{2}{*}{$P=0.204 n s$} \\
\hline Hemorrhagic & 26 & 40.0 & \\
\hline
\end{tabular}

Table (2): prevalence of modifiable risk factors in acute Ischemic and Hemorrhagic stroke patient ( $N=60)$.

\begin{tabular}{|l|c|c|c|c|c|c|c|}
\hline \multirow{2}{*}{ Type of stroke Risk factors } & \multicolumn{2}{|c|}{$\begin{array}{c}\text { Ischemic stroke } \\
(\mathbf{N = 3 4 )}\end{array}$} & \multicolumn{2}{c|}{$\begin{array}{c}\text { Hemorrhagic } \\
\text { stroke (N=26) }\end{array}$} & \multicolumn{2}{|c|}{$\begin{array}{c}\text { Total } \\
\mathbf{N}=\mathbf{6 0})\end{array}$} & $\begin{array}{c}\text { Significance } \\
\text { test }\end{array}$ \\
\cline { 2 - 8 } & $\mathbf{N}$ & $\mathbf{\%}$ & $\mathbf{N}$ & $\mathbf{N}$ & $\mathbf{N}$ & $\mathbf{\%}$ & $\mathbf{p}$ value \\
\hline Hypertension & 20 & 58.82 & 8 & 30.76 & 28 & 46.66 & $\mathrm{P}=0.271 \mathrm{~ns}$ \\
\hline Ischemic Heart disease & 5 & 14.70 & 4 & 15.38 & 9 & 15 & $\mathrm{P}=0.625 \mathrm{~ns}$ \\
\hline Diabetes mellitus & 5 & 14.70 & 1 & 3.84 & 6 & 10 & $\mathrm{P}<0.02 *$ \\
\hline Coagulopathy & -- & -- & 5 & 19.23 & 5 & 8.33 & -- \\
\hline Obesity \& Lack of physical exercise & 6 & 17.64 & 3 & 11.53 & 9 & 15 & $\mathrm{P}=0.357 \mathrm{~ns}$ \\
\hline History of previous stroke & 15 & 44.11 & 3 & 11.53 & 18 & 30 & $\mathrm{P}=0.251 \mathrm{~ns}$ \\
\hline
\end{tabular}

(N.B):- N.S P>0.05no significance $* p<0.05$ significance

$* * p<0.001$ moderate significance $\quad * * * p<0.000$ high significance

Table (3): prevalence of Non modifiable risk factors in acute Ischemic and Hemorrhagic stroke patient $(\mathrm{N}=60)$.

\begin{tabular}{|c|c|c|c|c|c|c|c|}
\hline \multirow[t]{2}{*}{ Type of stroke Risk factors } & \multicolumn{2}{|c|}{$\begin{array}{c}\text { Ischemic stroke } \\
(\mathbf{N}=34)\end{array}$} & \multicolumn{2}{|c|}{$\begin{array}{l}\text { Hemorrhagic } \\
\text { stroke }(\mathrm{N}=26)\end{array}$} & \multicolumn{2}{|c|}{$\begin{array}{c}\text { Total } \\
(\mathbf{N}=60)\end{array}$} & \multirow{2}{*}{$\begin{array}{c}\begin{array}{c}\text { Significance } \\
\text { test }\end{array} \\
\text { p value }\end{array}$} \\
\hline & $\mathbf{N}$ & $\%$ & $\mathbf{N}$ & $\%$ & $\mathbf{N}$ & $\%$ & \\
\hline$\geq 55$ years & 23 & 67.64 & 15 & 57.69 & 38 & 63.33 & $\mathrm{P}<0.04 *$ \\
\hline$\leq 55$ years & 11 & 32.35 & 11 & 42.30 & 22 & 36.66 & \\
\hline Sex & & & & & & & $P=0.527 \mathrm{~ns}$ \\
\hline Male & 14 & 41.17 & 13 & 50 & 27 & 45 & \\
\hline Female & 20 & 58.82 & 13 & 50 & 33 & 55 & \\
\hline
\end{tabular}

Table (4): relation of acute stroke type and length of hospital stay:- $(\mathrm{N}=60)$.

\begin{tabular}{|l|c|c|c|c|c|}
\hline \multirow{2}{*}{ Type of stroke Length of hospital stay } & \multicolumn{2}{|c|}{$\begin{array}{c}\text { Ischemic stroke } \\
(\mathbf{N}=\mathbf{3 4})\end{array}$} & $\begin{array}{c}\text { Hemorrhagic stroke } \\
(\mathbf{N = 2 6})\end{array}$ & $\begin{array}{c}\text { Significance } \\
\text { test }\end{array}$ \\
\cline { 2 - 6 } & $\mathbf{N}$ & $\mathbf{\%}$ & $\mathbf{N}$ & $\mathbf{\%}$ & \\
\hline For 5 days. & 14 & 41.17 & 4 & 15.38 & \multirow{2}{*}{$\mathbf{P}<\mathbf{0 . 0 2} *$} \\
\hline$\leq 5$ days. & 12 & 35.29 & 16 & 61.53 & \\
\hline Number of patient die & 8 & 23.52 & 6 & 23.07 & $\mathrm{P}=0.251 \mathrm{~ns}$. \\
\hline
\end{tabular}

(N.B):- N.S P>0.05no significance

$* * p<0.001$ moderate significance
$* p<0.05$ significance

$* * * p<0.000$ high significance 
Figure (1):- prevalence of acute stroke type.

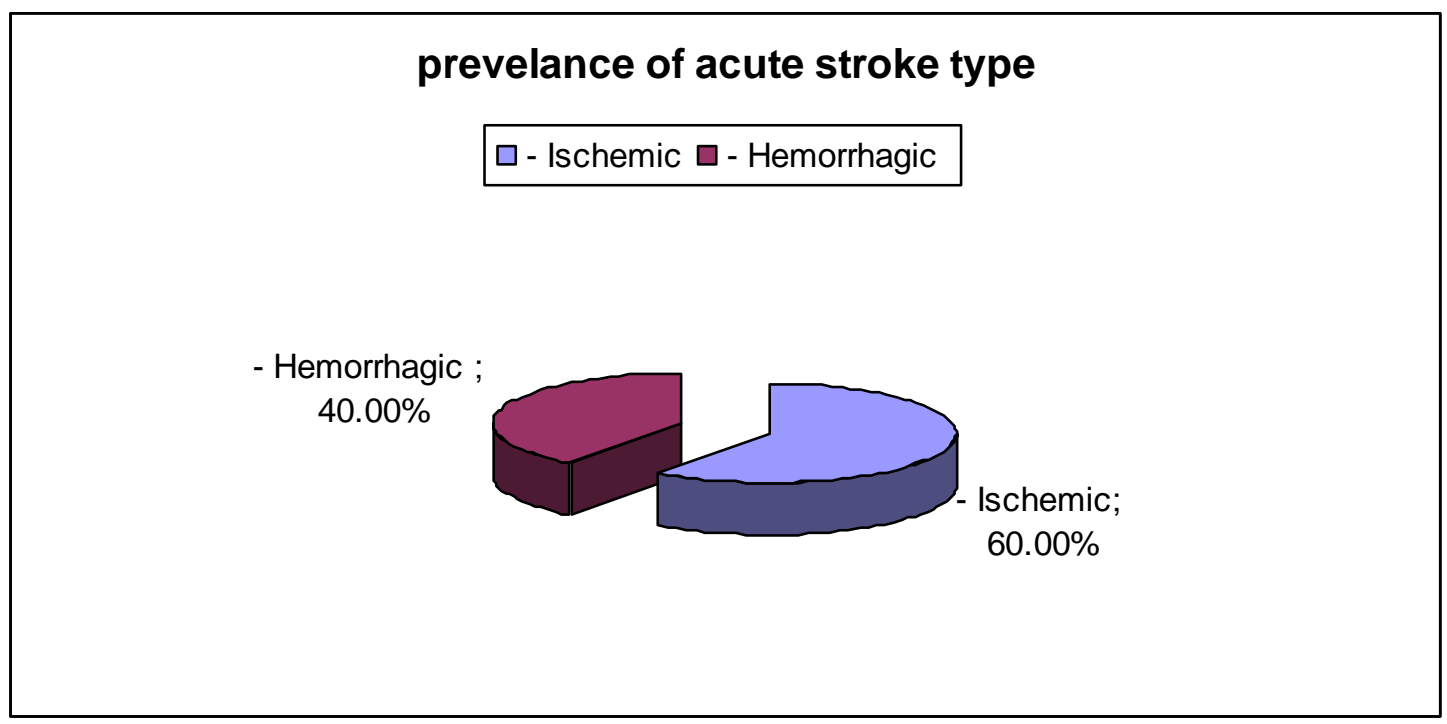

Figure (2):- prevalence of modifiable and non-modifiable risk factors in acute ischemic and Hemorrhagic stroke.

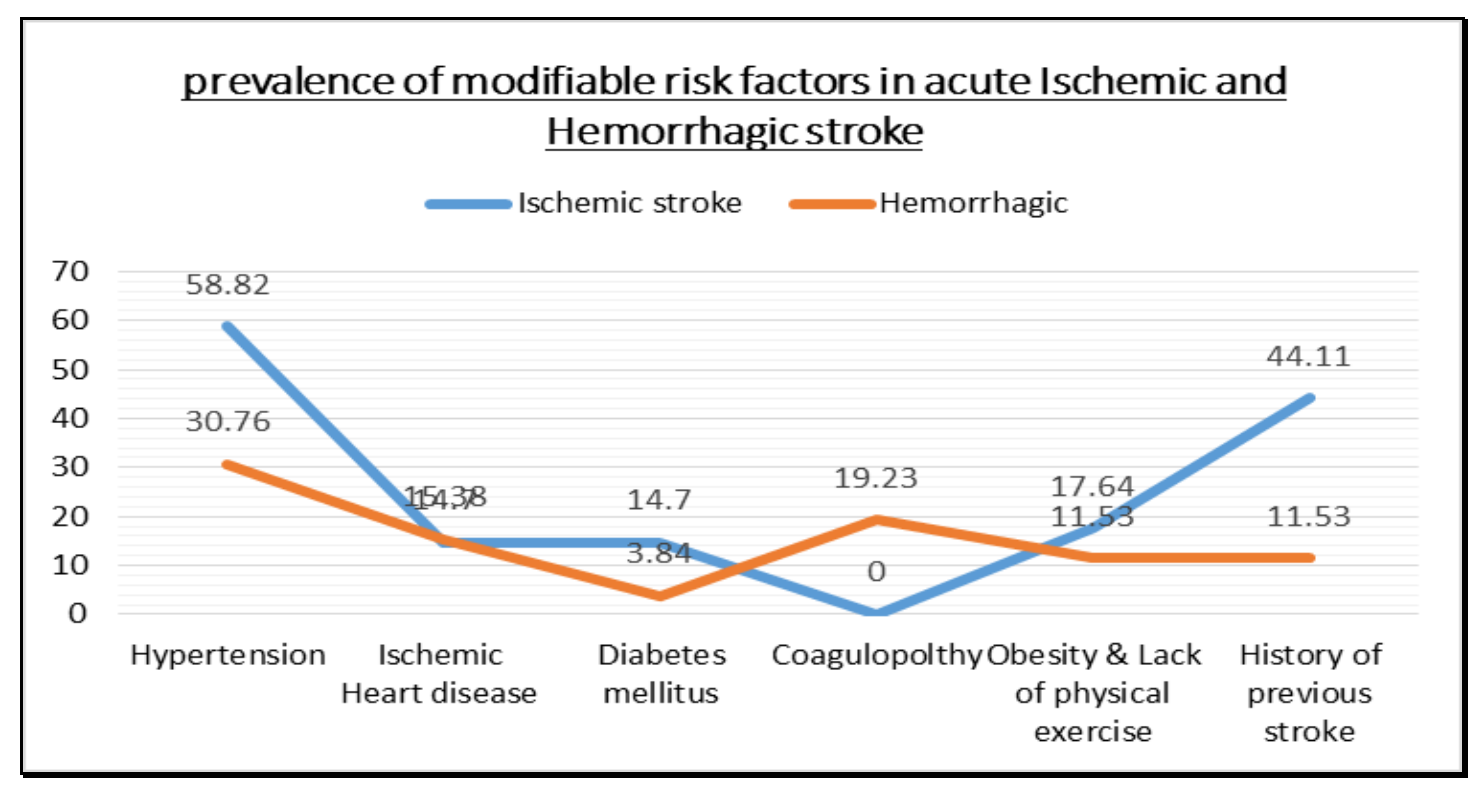

Table (1):- show the prevalence of acute ischemic and hemorrhagic stroke in the studied sample that revealed majority of cases were ischemic $(60.0 \%)$ and $(40.0 \%)$ for hemorrhagic cases.

Table (2):- show the prevalence of modifiable risk factors associated with acute ischemic and hemorrhagic stroke. it show the hypertension as the first and important factors of acute stroke either in ischemic or hemorrhagic type with $(58.82 \% \& 30.76 \%)$ in both types respectively, followed by ischemic heart disease with $(14.70 \%$
\& $15.38 \%$ ) in both stroke types respectively. While DM consider one of most common risk factors with $(14.70 \% \& 3.84 \%)$ in both stroke type respectively.

Table (3):- show the prevalence of modifiable risk factors associated with acute ischemic and hemorrhagic stroke. The table revealed that majority of sample was greater than 55years for both types consequently and show significant difference with $\left(\mathrm{p}<0.03^{*}\right)$. While regard patient gender show the percent of female patient higher in ischemic type than male ( $41.17 \%$ to $58.82 \%$ ) 
and it is equal in hemorrhagic stroke for both gender.

Table (4):- show the relation between type of acute stroke and length of hospital stay, the length of stay is more in hemorrhagic stroke than ischemic stroke with significant difference between both types of acute stroke $(\mathrm{p}<0.02 *)$.

Figure (1):- it show prevalence of acute stroke; where the percent of ischemic stroke was more than hemorrhagic one ( $60 \% \& 40 \%$ respectively).

Figure (2):- it show prevalence of modifiable risk factor in both ischemic and Haemorrhagic stroke; as hypertension was the most common modifiable risk factor in both groups $(58.28 \%$ in ischemic stroke and $30.76 \%$ in hemorrhagic one).

\section{Discussion}

Age is one of the strongest determinants of stroke, incidence rises with age, nearly doubling every decade after age 55, and the majority of strokes occur in persons older than 65 (Thom et al., 2006). The present study shows that majority studied patients were old age in the studied patient with no significance difference between the both groups. These findings were in line with the study done by (Ayman Y., Essa, 2011; Mumtaz, et al, 2009) who studied 88 patients with acute cerebrovascular stroke in Department of Medicine, Saidu Teaching Hospital, were the mean age $(65.9 \pm 9.15)$ in his sample.

As regard the gender, the present study revealed that majority of patients were females with no significant difference. This comes in contrast with the study done by (Somay et al, 2000) in Turkey who mentioned that Among 401 patients with acute CVS (70.6\%) were males while (29.4\%) were females. And in the study done by (Osuntokun et al, 2001) on 318 patients admitted with acute CVS in Africa male patients constituted $(70 \%)$ and female patients $(30 \%)$.

The type of stroke, the current study revealed that ischemic stroke is more common than hemorrhagic stroke with a significant difference ( $\mathrm{P}<0.03)$. This finding also come in line with (Ayman Y. E. Essa, 2011) his study was conducted on 425 patients admitted to Alexandria main university hospital with acute cerebrovascular stroke. Who found that the number of patients with cerebral infarction was (68.0\%) with show significant difference $(\mathrm{P}<$ $=0.021$ ) if compared with patient had intracranial hemorrhage who was $(32.0 \%)$ in the same study. In the study of (Mumtaz, et al., 2009) 60\% of patients had cerebral infarction and $(40 \%)$ had intracranial hemorrhage. In non European surveys such as Japan it was found at $(30.5 \%)$ for hemorrhage and $(69.5 \%)$ for ischemic (Peter, 2001), other national studies, where in Ain shams (Cairo, Egypt) study it was (22\%) for hemorrhage and $(75 \%)$ infarction (Hany, 2003).

Regarding the risk factors of the studied patients who admitted to Emergency department at Assuit University Hospital with Acute stroke hypertension, diabetes mellitus, Ischemic Heart Disease and Obesity where the most common with non statically difference between both study and control groups. In the current study hypertension seems to be the more common associated risk factors in acute stroke patient with a percentage of $(46.66 \%)$ in all studied sample. This is in line with the study done by (Fawi, et al 2009) that was a Prospective hospital-based study carried out in the Neurology department of Sohag University hospital, involved 467 consecutive stroke patients, who mentioned that hypertension was the more frequent risk factor reported in $(42 \%)$ of patients in the study populations in his study. While In the study done by (Mumtaz et al., 2009) show that the prevalence of hypertension was higher with (75\%) among Patients admitted with acute CVS and (Ayman Y., Essa, 2011) reported that $(88.5 \%)$ of patients admitted with acute cerebrovascular stroke had history of hypertension in his study

As DM increase the likehood of large and small artery occlusive disease but apparently does not predispose to haemorrahge or to poor functional outcome (Karapanayiotides, et al, 2004). In the present study diabetes mellitus constituted $(10.0 \%)$ of the acute stroke in the total studied patient and was higher in acute ischemic type. That agree with the study done by (Mumtaz Ali Marwat et al., 2009) where the prevalence of DM was $(54.5 \%)$ among Patients admitted with acute CVS (Ayman Y., Essa, 2011) reported that $(68.2 \%)$ of patients admitted with acute cerebrovascular stroke had history of DM in his study that still a high percent compared with other studies.

Regarding Ischemic Heart Disease the current study results revealed that there was no significant difference between both types regard IHD. (Somya et al., 2001) reported in their study in turkey that $(40.1 \%)$ of the patients with acute stroke had history of IHD. (Fawi, et al., 2009), study show that $(32.8 \%)$ of his studied sample where IHD.

(Fawi, et al., 2009), mentioned that (10.0\%) of the studied sample were obese, that agree with the current study obesity where founded in $(15.0 \%)$ of the studied sample. 
On the other hand, in the present study history of previous strokes was not significantly difference among acute stroke patients in the study and control group respectively. This is in line with study done by (Ayman Y., Essa, 2011), which reported that history of previous strokes was not significantly among acute cerebrovascular stroke patients that where $(19.3 \%)$ of the patients had history of previous strokes. And this was similar to what (Salma, 2000) had found that (22\%) of the patients had history of previous strokes.

As regarding the relation between type of stroke and mortality rate, current study stated that mortality rate higher in hemorrhagic stroke than in ischemic type. This agrees with study done by (Ayman Y. E. Essa, 2011), who documented that of 184 patents $(85.2 \%)$ of the died had hemorrhagic stroke while $32 \quad(14.8 \%)$ had ischemia $(\mathrm{p}=0.001)$.

\section{Conclusion and Recommendations}

Based on the findings of the present study, it can be concluded that nursing care for acute stroke should address multiple body systems, with many actual and potential problems. Another important aspect of nursing management is the identification and modification of risk factors. Education of the patient and family is an invaluable service to help to avoid future stroke. The best approach to reduce the burden of stroke remains prevention. Prevention plays a crucial role in counteracting morbidity and mortality related to stroke. It has been estimated that $50 \%$ of stroke are preventable through control of modifiable risk factors and lifestyle changes.

Based on the study findings, the following recommendations are suggested:

- Developing educational programs for raising public awareness of stroke risk factors and warning signs and identifying those at risk of stroke.

- Providing high quality and standardized assessment protocol of individual stroke risk for emergency nurses.

- Reapplying this research on a larger probability sample acquired from different geographical areas in Egypt for generalization.

\section{References}

1. Adams H., Del Zoppo G., Alberts M., 2007: Guidelines for the early management of adults with ischemic stroke. A guideline From the American Heart Association/American Stroke Association
Stroke Council, Clinical Cardiology Council, Cardiovascular Radiology and Intervention Council, and the Atherosclerotic Peripheral Vascular Disease and Quality of Care. Outcomes in research interdisciplinary working groups. 38:1655-711

2. American Heart Association: Heart disease and stroke statistic-2005: update, Dallas, 2005, The Association.

3. American Heart Association: stroke risk factors (2006): available at www.americanheart.org/presenter.jhtml?iden tifier $=9217$.

4. Ayman Y., Essa, Tamer A., Helmy, Sameh S., El Batch, (2011): Neuropsychiatry Department; Critical Care Medicine, Study of Incidence, Risk Factors and Outcome of Acute Cerebrovascular Stroke Patients Admitted to Alexandria Main University Hospital, American Science; 7(11):316-329.

5. Carmona R., (2006): The health consequence of smoking: a report of the surgeon general. Available at www.surgongeneral.gov/liberary/smoking consequence

6. Chiuve, S., Rexrode, K., Spiegelman, D., (2008). Primary prevention of stroke by healthy lifestyle. Circulation, 118(8), 947301.

7. G., Fawi, F., Corea, M., Abbas, M., Thabit, G., Comi, (2009). Neurology Department, Sohag Faculty of Medicine, Sohag University, Southern Egypt Stroke Study: Case Fatality Rates in a HospitalBased Setting,

8. G.somay, Ozkaya B., Sagduyu A., et al. The Ege Stroke Registry: 2000: A Hospital-Based Study in the Aegean Region, Izmir, Turkey. Cerebrovascular Dis; 8:27888. 25.

9. G.somay, Ozkaya B., Sagduyu A., et al. The Ege Stroke Registry: A., HospitalBased Study in the Aegean Region, Izmir, Turkey. Cerebrovascular Dis (2000): 8:278-88. 25.

10. Heart and stroke foundation of Canadian (2006): The growing burden of heart disease and stroke, available at http//dsp_psd.pwgsc.gc.ca/collection/HI-102003E.Pdf. Augest.30 National Stroke Foundation. Clinical guidelines for acute stroke management. Melbourne: NSF, 2007.

11. Heart disease and Stroke statistics- 2010: update. A report from the American Heart Association, Circulation 121:e46, 2010. 
12. Jane Williams, Lin Perry and Caroline Watkins. 2013: Acute Stroke Nursing, 1 edition (May 7, 2013). Wiley-Blackwell, page 368 available at http://www.amazon.com/Acute-StrokeNursing-ebook/dp/B00CQ2U7O4.

13. Julie Considine, Bree McGillivray. (2010): An evidence-based practice approach to improving nursing care of acute stroke in an Australian Emergency Department, Journal of Clinical Nursing, (19), 138-144)

14. Kuruvilla, J., Essential of critical care nursing, (2007): first edition. Chapter 15. Pages 530-564.

15. Lewis, S., Heitkemper M., Dirksen, S., Garber, P., Et al., (2007). medical-surgical nursing, assessment and Mangment of clinical problems , seventh edition, chapter58, pages 1502-1526.

16. Luders, S., (2007). Drug therapy for secondary prevention of stroke in hypertensive patients: Current issues and options. Drugs, 67(7), 955-963

17. Morton P., Fontaine D., Hudak C., Gallo B., (2005): Critical Care Nursing A Holistic Approach, 8th ed, Lippincott; 815-823.

18. Muir K., Buchan A., von Kummer, R., Rother J., \& Baron J., (2006).

19. Mumtaz Ali Marwat, Muhammad Usman, Muhammad Hussein Gamal Journal of Medical Sciences January-June (2009):Vol. 7, No. 1.

20. National Stroke Association, 2009: Journal of Stroke and Cerebrovasular Disease, Vol.18, No 3(May- June), pp 203-207.

21. Romano J., Sacco R., 2008: progress in secondary stroke prevention. Ann Neurol 63:818,.

22. Sahni R., Weinberger J., Mangment of intracerebral hemorrhage. Vasc Health risk management. (2007): - 3:701-709.

23. Thom T., Haase N., Rosamond W., (2006): Heart disease and stroke statistics-2006 update: a report from the American Heart Association Statistics Committee and Stroke Statistics Subcommittee. Circulation; 113: 85. 